\title{
MULHERES NO POLICIAMENTO OSTENSIVO E A PERSPECTIVA DE UMA SEGURANÇA CIDADÃ
}

Márcia Esteves de Calazans

\begin{abstract}
Resumo: Valendo-se de estudo empírico com mulheres policiais da Brigada Militar do Rio Grande do Sul, irá se discutir o processo de inserção feminina no aparelho policial militar e como a violência, presente na cultura institucional desta polícia, funciona como um dispositivo estratégico que transforma as mulheres em policiais militares.

Palavras-chave: cultura; gênero; trabalho; subjetividade.

Abstract: Based on empiric observations of female members of the Military Brigade of the State of Rio Grande do Sul, this article will discuss the process of women's insertion into the military police structure. It will further address how violence, present in the institutional culture of this police force, acts as a strategic tool in this insertion.

Key words: culture; gender; work; subjectivity.
\end{abstract}

$\mathrm{N}$ o Brasil, é muito recente o debate integrado entre as reformas policiais, as políticas de ações afirmativas e as concepções de segurança pública quanto à inserção feminina nas polícias militares. Tal quadro acentua-se no que concerne ao entendimento do aparelho policial militar enquanto uma nova tecnologia da produção social na constituição de homens e mulheres em policiais. Por muito tempo, esse debate esteve à margem das discussões do mundo acadêmico, da sociedade civil e das gestões de segurança, adquirindo relevância nesses espaços somente a partir da década de 90 , com a crise da segurança. Contudo, os elementos da tríade reforma policial, concepções de segurança pública e inserção feminina nas polícias militares brasileiras não aparecem interseccionados nessas discussões. Assim, essa inserção e suas práticas cotidianas no ofício de policial, quando chegam ao debate, colocam-se sob o olhar naturalista, essencialista, segundo o qual as mulheres são menos violentas por "natureza".

Observa-se que pesquisas sobre a participação das mulheres nas forças policiais responsáveis pelo policiamento ostensivo são ainda raras no Brasil, e há poucos estudos disponíveis nesse campo. Estes estudos, ${ }^{1}$ assim como aqueles realizados em outros países, como França (1991), Espanha (1994), Austrália (1999), Inglaterra (1990) e EUA (2000), revelam uma multiplicidade de questões decorrentes da presença feminina nas polícias, porém, poucos deles abordam as relações entre os aspectos de formação nas academias de polícia, construção de gênero, constituições dessas mulheres em policiais e suas práticas cotidianas no policiamento ostensivo. Nesses trabalhos, observamos o predomínio da metodologia quantitativa, apresentando uma espécie de mapeamento da distribuição de mulheres em unidades de policiamento. Por outro lado, autores como Delhomez (França, 1991) e Fernández (Espanha, 1994) trouxeram contribuições relevantes para nossos objetivos, visto que desenvolveram estudos com base em uma metodologia qualitativa, centrados no eixo da dificuldade de inserção feminina nas forças policiais, analisando as políticas de ações afirmativas. Essa abordagem pode ser justificada pela existência, em seus países, de leis antidiscriminatórias, as quais alavancaram o ingresso feminino nas forças policiais. Porém, não encontramos estudos que concebessem o aparelho policial como uma tecnologia da produção social na constituição de mulheres em policiais e analisassem o 
modo como essas mulheres constituem-se e colocam-se nas práticas cotidianas do ofício de polícia, em especial no policiamento ostensivo.

No Brasil, a filosofia tradicional de policiamento é movida pelo espírito belicoso do Exército Nacional e por ideologias machistas, assim, o tratamento para a inserção de mulheres nos quadros das polícias dá-se de uma forma muito limitada e com pouca visibilidade. Atualmente, nos estados brasileiros, encontramos os mais diversos tratamentos à incorporação de mulheres nas polícias militares, manifestos sobretudo por meio de restrições legais e informais, o que vem dificultando a inserção e a ascensão na carreira. Por exemplo, no Distrito Federal, há uma lei de 1998 que restringe a $10 \%$ a participação feminina no efetivo da PM, o mesmo ocorrendo no Mato Grosso, onde, em um concurso realizado em 2001, a participação feminina também foi limitada a $10 \%$ de um total de 800 vagas oferecidas. Atualmente, na maioria dos estados, o efetivo de mulheres não pode ultrapassar $10 \%$ do total, e a participação feminina nas polícias militares corresponde a, aproximadamente, $5 \%$ do conjunto do efetivo.

Atualmente, em 26 estados da Federação brasileira, há a participação de mulheres no ofício de polícia. O Estado de São Paulo foi pioneiro na inserção feminina nos quadros policiais, no ano de 1955, e alguns outros estados criaram as companhias femininas na década de 70, tendo havido a grande concentração de inclusão de mulheres na década de 80. Essa inserção deu-se com a criação do Pelotão de Polícia Militar Feminina ou das Companhias Femininas, particularidade na qual poucos estados diferem.

Seguindo o pensamento de Jennifer Brown (1997), do College of Police and Security Studies, da Eslovênia, apontamos que, em termos mundiais, o processo de inserção da mulher na polícia relaciona-se a quatro aspectos, a saber: na Europa, o contexto do recrutamento de mulheres situa-se em momentos de crise das forças policiais (por exemplo, deslocamento do efetivo masculino em períodos de guerra, ou crises de credibilidade, com forte deterioração da imagem pública das polícias); existência de uma cultura policial feminina, que estaria identificada e valorizaria as formas preventivas - portanto, menos truculentas - de policiamento; a despeito dessa realidade, há restrições às tarefas femininas, sustentadas na noção de que as mulheres não são capazes de assumir todas as formas de ação de polícia e a conseqüente tendência de atribuir-lhes sobretudo funções burocráticas ou atividades associadas, no imaginário, a extensões do mundo doméstico; necessidade de equiparação de oportunidades (investimento em ações antidiscriminatórias e no enfren- tamento dos casos de assédio sexual). Fazer-se um breve resumo da presença feminina em outras polícias do mundo permite situar-se o quadro em que se movem as mulheres nas polícias, principalmente para uma análise reflexiva acerca das semelhanças dos processos de inserção da mulher nesse aparelho.

Nos EUA, as mulheres entraram para a polícia (Prenzler, 2000) no meio do século XIX, assumindo o poder de polícia em torno de 1910. Na maior parte do século XX, as mulheres atingiram 1\% do efetivo de pessoal; ainda em 1972 esse percentual chegava a $2 \%$ e, em 1997, havia chegado apenas a $12 \%$.

$\mathrm{Na}$ Austrália, ocorreu uma expansão rápida do número de policiais femininas nos anos 80 , principalmente em nível estadual, onde o policiamento é concentrado. Em 1991, $17,6 \%$ da polícia federal australiana era composta de mulheres. A maioria dos estados, agora, tem a admissão de mulheres em níveis entre $25 \%$ a $35 \%$. Contudo, elas desempenham de $9 \%$ a $13 \%$ dos trabalhos inferiores no baixo escalão. Os números de 1991/92 indicam que o crescimento do recrutamento feminino ficou em torno de $30 \%$, mas poucas mulheres ocupam níveis mais elevados, no alto escalão.

$\mathrm{Na}$ Inglaterra, as barreiras discriminatórias foram derrubadas em 1989, parcialmente em antecipação à legislação introduzida em 1992. No caso do serviço de polícia do sul do País de Gales, no início dos anos 80, uma ação tomada como ato antidiscriminação, acionada por candidatas femininas rejeitadas no serviço policial, levou ao abandono do sistema de quotas. Assim, nestes países, as mulheres entraram para a polícia em grande número devido à proteção da legislação antidiscriminatória.

Em 1934, as mulheres começam a participar da polícia francesa ocupando um cargo denominado assistente de polícia, com uma carreira limitada quanto às atribuições policiais, cumprindo missões voltadas para crianças em situação de riscos morais ou psíquicos e prestando vigilância em via pública. Pouco a pouco, elas passaram a ingressar no corpo de inspetores da prefeitura, ainda que permanecendo restritas a serviços menores. Somente em 1982, um projeto governamental garantiu condições de emprego à força feminina, quando o conselho superior da função pública autorizou igualdade para o recrutamento de homens e mulheres, observando uma proporção limite por antecipação, garantia essa que elevou de $10 \%$ para $20 \%$ a participação feminina. Tal medida considerava que as resistências à inserção feminina nas polícias eram reais, e que ignorar as diferenças gerava um erro na luta pela igualdade e legalidade. Assim, apoiando-se na ação 
diretiva européia de 1976 contra a discriminação, esse projeto governamental assegurava melhores condições de emprego, a exemplo do que se verificou em outros países onde essa legislação atuou como elemento catalisador para mudanças dessa natureza.

Em alguns países, as porcentagens de ingresso de mulheres na força policial têm se incrementando consideravelmente nos últimos tempos, como no caso da Alemanha, onde esse índice fica entre $40 \%$ e $50 \%$. Ainda assim, não podemos falar de uma autêntica representatividade feminina na polícia (Walter, 1999:357), pois, em outros países onde ela é também elevada, os percentuais chegam a apenas $20 \%$. No caso das polícias metropolitanas de Londres, da Inglaterra e de Gales, por exemplo, a participação das mulheres é de $14 \%$, e na Grécia e na Estônia, de $15 \%$.

No Brasil, a concentração de entrada das mulheres na polícia deu-se na década de 1980 , coincidindo com um momento de crise da própria instituição policial que, por sua vez, refletia uma crise mais ampla do próprio modo de organização do trabalho nas sociedades contemporâneas. O trabalho policial, que vinha sendo visto, necessariamente, como uma ocupação masculina, apresenta desde então uma estrutura que está sofrendo mudanças, na medida em que entram em crise valores característicos da organização, como a força física e a identificação tradicional com a figura masculina. Passaram-se a buscar outros valores condizentes com a realidade atual, como a inteligência, a capacidade de resolução de conflitos, a inovação e o trabalho em equipe, uma vez que os policiais defrontam-se com novas situações em que não é tão necessária a força física, tais como a redução de situações potencialmente violentas e conflituosas e o atendimento a coletivos que exigem tratamento diferenciado. Contudo, a ausência de estudos sobre a inserção feminina nas polícias militares brasileiras, focalizando a constituição das mulheres em policiais, e o fato de, no imaginário da população e dos operadores de segurança pública, existir a crença de que a violência presente nas forças policiais é menor entre as mulheres e que, por isso, elas teriam um papel saneador, são elementos os quais, de alguma forma, têm contribuído para a efetivação e atualização de ações violentas nas práticas cotidianas do policiamento ostensivo.

No âmbito do projeto financiado pela Fundação Ford Alternativas Democráticas do Ofício de Polícia para o Século XXI, Grupo de Pesquisa Violência e Cidadania IFCH/UFRHS, coordenado pelo Prof. Dr. José Vicente Tavares dos Santos, concluímos, em abril de 2003, o es- tudo intitulado A Constituição de Mulheres em Policiais: um estudo sobre policiais femininas na Brigada Militar do Rio Grande do Sul. Este trabalho dá visibilidade ao processo de inserção feminina no aparelho policial militar e, sobretudo, ao modo como a violência presente na cultura dessa polícia funciona como um dispositivo estratégico constituinte de mulheres em policiais militares, evocando as práticas arbitrárias no ofício de policial. O presente artigo articula-se nesse campo empírico. Delimitaremos, de modo mais sistematizado, os pressupostos amplos e gerais que sustentam essa discussão e a análise que efetivamos, os quais compõem um relatório de pesquisa (Tavares dos Santos, 2003) e uma dissertação de mestrado. ${ }^{2}$

O primeiro pressuposto deste artigo permite conceberse a cultura como um campo de luta e contestação em que se produzem tanto os sentidos quanto os sujeitos que constituem os diferentes grupos sociais em sua singularidade. Stuart Hall é um dos autores atuantes no campo dos Estudos Culturais que discute a centralidade da cultura na contemporaneidade e para quem a expressão "centralidade da cultura indica a forma como a cultura penetra em cada recanto da vida social contemporânea, fazendo proliferar ambientes secundários, mediando tudo" (Stuart Hall, 1997:22). Compreende-se, assim, que a cultura precisa ser analisada quanto ao seu impacto "na constituição da subjetividade, da própria identidade e da pessoa como um ator social" (Stuart Hall, 1997:24). Dessa forma, entendemos que os processos de produção de identidades não são simplesmente influenciados pela cultura, mas que as identidades são, elas mesmas, produções culturais (Wortmann, 2001).

O segundo pressuposto enfatiza compreendermos o trabalho como conjunto de processos pelos quais indivíduos são constituídos ou se constituem em sujeitos de uma cultura, o que envolve um complexo de forças e de processos de aprendizagem.

O terceiro pressuposto ressignifica o processo de subjetivação como uma série de forças e vetores e compreende singularidade, a saber, o modo pelo qual o indivíduo apropria-se dessas forças e cria modos particulares de ser. Desta forma, compreendemos a subjetividade como um processo de formação e dissolução de figuras, uma série de forças e vetores incidentes sobre os meios que habitam a subjetividade, produzindo uma configuração, as quais provocam uma reação a um modo de existência. Esse é um processo contínuo de formação e diluição, o que faz da subjetividade um sempre outro. A experiência da desestabilização é reiteradamente repetida ao longo de nos- 
sa existência, e a experiência criadora tem a ver com a forma como vamos lidar com o mal-estar provocado pela desestabilização originando em modos singulares de ser (Guattari; Rolnik, 1986). Porém, ao longo da nossa pesquisa, observamos que os dispositivos disciplinares que pautam a relação interna do aparelho policial militar apontam um processo de formatação da subjetividade nos termos de um modelo hegemônico e de uma impossibilidade de ruptura com este modelo. $\mathrm{O}$ modo burocrático-disciplinar presente na organização do trabalho policial configura um espaço hegemônico, como uma tecnologia da produção social, basilar para a compreensão da constituição de mulheres e homens em policiais militares.

Finalmente, o quarto pressuposto amplia a noção de gênero para além da discussão de papéis e funções de mulher e de homem, para argumentar que ela engloba todas as formas de construção social, cultural e modos de subjetivação. Para Meyer, se o conceito de gênero marca a questão relacional e a construção de homens e mulheres, seus discursos devem incluir uma pluralidade de formas de existir, ocorrendo uma ampliação para as diferentes pertenças a distintos grupos. Torna-se importante a articulação de outros marcadores sociais como classe, raça, nacionalidade, profissão, etnia, entre outros, os quais são construídos e significados socialmente, assinalando diferenças, produzindo desigualdades e formando hierarquias.

Em suma, o suporte teórico brevemente esclarecido permite compreendermos o aparelho policial militar como uma tecnologia da produção social na constituição de mulheres e homens em policiais militares.

A ausência de problematização das concepções de segurança pública, atividade policial e inserção feminina nos quadros da Polícia Militar permite formar-se, no imaginário dos gestores de segurança pública e da população em geral, a crença de que as mulheres são mais democráticas, menos violentas no exercício do policiamento ostensivo. Assim, à medida que surgem novas concepções de segurança pública, levando a alterações nas ações de polícia (por meio de políticas preventivas, como o policiamento comunitário), associadas à crescente feminização do mercado de trabalho, esse imaginário permite supor-se haver um "novo" lugar para as policiais femininas. Tal idéia sugere que as mulheres estão se beneficiando da lógica institucional, da lógica do capital, uma vez que ingressam na organização pelas habilidades construídas no seu processo de socialização na família, na escola e nos demais diversos grupos e instituições, atendendo, então, ao novo perfil do policial.

No processo de inserção de mulheres no aparelho policial militar, quando os sujeitos trabalhadores assumem novos postos na hierarquia dos círculos de convivência, seu gênero é fonte de status e poder, condicionando o modo de inserção e posicionamento nos postos de trabalho, o que vai definindo o processo de exclusão-dominação. Dessa forma, observa-se que, mesmo na inclusão das mulheres na força policial, é evidente a permanência de modos de exclusão-dominação, posto que suas habilidades colocam-se como inatas, encaradas simplesmente como um modo "natural" de ser mulher. Portanto, a inserção feminina nos quadros das polícias do mundo é ilustrada por um processo de exclusão-dominação, variável presente nos estudos qualitativos encontrados a partir de uma revisão bibliográfica internacional e nacional.

Beneficiando-se da lógica do capital, as mulheres chegaram às instituições policiais no momento de mutações, precarização, globalização e de feminização do mundo do trabalho e encontraram, no interior do aparelho policial militar, uma estrutura vertical, pautada pela divisão hierárquica do trabalho, como um modo e meio totalizante de mediação de relações. Esses modo e meio são determinados, envolvidos e sustentados institucionalmente pelos chamados círculos de convivência de oficiais e praças, passando a ter, no gênero dos trabalhadores, mais uma fonte de referência nas diversas lutas de poder. Assim, identificamos que o processo de inserção feminina nas polícias constitui um processo de características mundiais, guardadas as devidas proporções, o qual se caracteriza por um modo de inclusão-exclusão-dominação.

Observamos que, para se adequarem ao rigor do "ser policial", essas mulheres suportaram uma longa e árdua aprendizagem, como uma espécie de sacrifício físico, encontrando, na suportabilidade, a garantia de tornaram-se "donas de si", de apropriarem-se de seus destinos, ainda que tal "propriedade" fosse limitada, principalmente, quanto à autonomia no ambiente de trabalho e que as aspirantes fossem levadas à exacerbada submissão ao autoritarismo próprio da instituição. O desejo de tornarem-se donas de seus destinos, buscando estabilidade no mundo do trabalho, o qual se encontrava em franca precarização, mostrava-se consoante o momento de "transformações" no ofício de polícia, pois as "novas" concepções de segurança pública mostravam-se orientadas para os cuidados e prevenções, além de estarem mais burocratizadas, encontrando, nas mulheres, qualidades necessárias a essa implementação. Há, logo, uma associação entre a profissionalização do trabalho policial e o ingresso de mulheres no aparelho policial militar, na perspectiva de uma polícia menos voltada para o uso da força e mais direcionada para a capacidade estratégica, exigências advindas das 
transformações pelas quais vêm passando o modelo de polícia e o próprio mundo do trabalho.

\section{O INTERIOR DO APARELHO POLICIAL MILITAR}

Observamos que a convivência e as relações estabelecidas no interior do aparelho policial militar pressupõem que o poder das estruturas não vale para um sujeito senão em sua expressão encarnada, sua presença real, tanto para homens, como para mulheres. Nesse entendimento, as condutas dos sujeitos tornam-se simbólicas (Melman, 2000) de uma falta, de uma falta essencial, a falta de acesso ao objeto que conta, que comanda, a falta do encontro com o que sua auto-referência diz que ela é. Essa dinâmica da institucionalidade cultural da Polícia Militar é originária da cisão institucional e, nessa cisão, encontra a sobredeterminação militar, a qual define e evoca as práticas arbitrárias do ofício de polícia. Assim, a violência coloca-se estrategicamente na institucionalidade cultural da polícia militar, como dispositivo constituinte de homens e mulheres em policiais militares.

Instaurar o medo e inibir e cercear o outro são meios pelos quais se consegue fazer respeitar os preceitos hierárquicos. Então, é sob os círculos que se estabelece o protótipo do sistema disciplinar, objetivando os comportamentos condicionados e enfatizando um compromisso com o bem-estar maior da corporação e um bem-estar menor do sujeito. A sobredeterminação militar e o fato de a polícia ser uma instituição secularmente masculina fazem com que os homens sejam o paradigma de emancipação e qualificação do desempenho profissional. A identidade feminina policial e a feminização da profissão policial ganham visibilidade na inserção em subgrupos de trabalho, ou mesmo em subtrabalhos dentro da instituição, dado o domínio masculino desse ofício, rechaçando-se, de diversas formas, a presença da mulher. O regime disciplinar e as sanções impostas aos descumprimentos de comportamentos esperados mostram que, nesse espaço de trabalho, não há uma relação de criação e de processo de singularização, pois, no constituir-se mulheres policiais, elas se apropriam dos componentes de subjetivação da própria instituição, tais como os recebem. Nesse contexto, é muito ilustrativo o fato de que, na cisão da institucionalidade cultural dessa polícia, a violência coloca-se como um dispositivo estratégico, como um componente da subjetivação. Não casualmente, observamos que, para as mulheres, o processo de aprendizagem do ofício de polícia seja iniciado na Jornada de Instrução Militar - JIM, ${ }^{3}$ e tal aprendizagem efetiva-se na "rua", quando os ensinamentos da JIM são colocados em prática.

\section{Atividade Extracurricular: Jornada de Instrução Militar - o Sentido de Ser Policial}

A sobredeterminação militar ganha visibilidade desde o curso de formação, quando as praças "iniciam-se" no ofício de polícia. Observamos, pelos relatos, que a Academia de Polícia Militar desenvolve atividades extracurriculares em que as práticas de JIM, ou práticas de campo, são vivenciadas por meio de técnicas, que são verdadeiras simulações de "campos de batalhas", onde o sujeito busca a sobrevivência. Baseada no sofrimento físico e psíquico, essa experiência leva o sujeito ao limite. Tais práticas refletem "os conflitos da polícia militar brasileira, que, pressionada a diluir seu caráter militar, incorpora novas exigências democráticas, mas, ao mesmo tempo, resiste em perder seus vínculos profundos com o militarismo" (Albuquerque; Machado, 2001:2). A fala a seguir, de uma praça, refere-se ao comando do treinamento:

"É, ele dizia assim... Ele dizia que os nossos rostinhos angelicais eram feitos pra matar. Ele dizia assim: 'Esses rostinhos angelicais foram feitos pra matar, matar, matar e matar'. Ia matutando aquilo na tua cabeça, que tu achava que tu era a Mulher Maravilha, né, podia tudo." Os treinamentos de JIM apontam a desautorização da modernização na Academia de Polícia Militar, obliterando a capacidade de uma nova formação, imprimindo uma imagem militarizada dos policiais, sejam homens ou mulheres - Rambo, Mulher Maravilha. Nesse tipo de treinamento, a transmissão de códigos culturais dá-se sob a dor física, e seus conteúdos deixam as marcas de uma identidade policial, a qual se constitui a partir de uma "memória-corpo". Ao mesmo tempo em que dizem querer esquecer o que vivenciaram, as praças identificam, nessa prática, a verdadeira preparação para o ofício de polícia, como se houvesse uma correlação entre aquilo que praticaram no treinamento e as atividades que desenvolverão no policiamento. Quando indagada sobre a aplicabilidade dos conhecimentos desenvolvidos na JIM, particularmente quanto ao uso da raiva mobilizada nessa vivência, uma policial diz: "Acho que sim, tu sai querendo matar..." A idéia da técnica e da inteligência sobreporem-se ao uso da força física fica rechaçada, conforme se constata por alguns depoimentos, o afrouxamento dessas práticas é visto como uma permissividade:

"Houve um curso de Sargento lá em Santa Maria, em 2000, e foi justamente lá porque eles tavam com sede 
de levar a turma pro rio, pro morro de noite e conseguiram. Só que, daí, aconteceu o seguinte ó, ligações dos próprios alunos pra Secretaria de Segurança, solicitando que acabassem com aquilo, porque os direitos humanos... e aí, o que aconteceu? Acabou."

Sob a égide de uma "nova polícia", o movimento para se extinguirem as ações violentas sofridas pelos praças ganhou visibilidade durante o governo Olívio Dutra (19992002), por meio do projeto de unificação de polícias, que contemplava cursos de formação unificados da Secretaria de Justiça e Segurança para quadros da Brigada Militar, Polícia Civil, Susepe e IGP. Esse projeto contemplava a atenuação da sobredeterminação militar, assim como a extinção das "Jornadas de Instrução" como atividades extracurriculares. Porém, pelas falas de algumas entrevistadas, pode-se perceber que a atividade extracurricular fundamentada em "técnicas de sobrevivência", de cunho militar, ainda hoje, no imaginário de algumas policiais praças, é o que dá sentido à aprendizagem para se transformarem em policiais:

"Porque aqui não dava para fazer, tinha aqui... tava fazendo um curso integrado. A única coisa que eles faziam era correr de madrugada. Foi no finalzinho de 1999/2000. Nós fomos pra lá, três turmas foram lá. Essa que tá tendo agora (...), teve um pouco em Montenegro, né, um pouco em Santa Maria, esconderam todo mundo. Porque lá, quando nós chegamos, eles fizeram o que eles queriam com a gente. Ali tava fechado, a gente tava no buraco, né? Cheguei lá, parecia que tava vendo um Coronel Massot na minha frente, umas grosserias e um oficial dizendo assim, ó: 'te posiciona, militar. Um militar não se apresenta assim. Volta lá’. Eu ficava escandalizada, né? Mas o que é isso? E, daqui a um tempo, eu já tava achando: 'tem que ser assim mesmo, tem que ser assim mesmo'. A gente vai entrando numas assim, que tu vê que tem necessidade disso. E, quando a gente tá lá, a gente fica se queixando: 'mas pra que isso? Pra quê? Pra quê? E aí, quando tu sai, tu vê assim, ó: tinha necessidade por causa disso'."

A atividade extracurricular por intermédio das JIM “(...) assume proporções na transmissão da identidade profissional maiores que o conjunto de disciplinas que compõem o amplo quadro curricular (Albuquerque; Machado, 2001:3). Nesse sentido, algumas praças referem que esse tipo de treinamento (JIM) está consonante as práticas cotidianas a serem enfrentadas, e que essa atividade prepara para a realidade a ser encontrada no ofício de polícia, em especial nas atividades de policiamento ostensivo. Observamos que a inserção feminina nas polícias militares bra- sileiras dá-se em meio ao conflito entre a "nova" polícia e a "velha" polícia. O interessante é que, sobretudo, algumas entrevistadas referem que as práticas de jornadas de instrução militar têm certa mobilidade:

"Agora ficou (...) da minha turma, ficou a sargento 'A', querendo passar pros próximos, pras próximas turmas, as mesmas situações que nós tivemos, aí, ela me comentou o seguinte, ó, ela disse que se sentia amarrada, que ela nem podia cobrar o fardamento engomado dos alunos. Não pode, não pode, porque é uma questão política."

À formação dessas alunas praças, incorporou-se o treinamento na selva ao estilo do exército militar, associado a atividades do tipo JIM e àquelas desenvolvidas nas ruas, no policiamento ostensivo. Conforme observamos, o objetivo dessas práticas é levar as alunas a perceberem que a identidade policial-guerreiro precede a legalidade. Em uma espécie de tortura desconstrutora da identidade e da autoridade simbólica, inscrevendo no corpo da aprendiz que ali se inicia uma lei para a qual não há apelação, é nesses treinamentos de "campo", em atividade extracurricular, "que se inicia a construção da polícia" (Albuquerque; Machado, 2001:14) contra a polis e de uma polícia sem polis. Nessas práticas, a "força" começa a consolidar-se numa "pirâmide hierárquica", pois bem sabemos que elas são coordenadas por oficiais. Instaura-se um processo de "mortificação do eu", como afirma Baumam (1998a). A modernidade trouxe-nos, com a burocratização, a racionalidade instrumental, dando origem à "desumanização" dos objetos e a perspectiva de que eles não merecem reivindicação alguma a uma subjetividade, surgindo a tendência a subordinar pensamento e ação à praticidade da economia e eficiência. A minúcia burocrática, facilita as práticas dissociativas (Bauman, 1998b), constitui uma cultura burocrática que nos possibilita ver a sociedade como objeto de administração.

"Nós sentadas no meio do pátio o dia inteiro, doze horas (...) um mês depois, eu não sabia que roupa botar pra ir numa festa. Eu não sabia me vestir, não sabia mais me vestir (...)

Eu chegava em casa, falava grosso, eu comecei a agir com as pessoas de fora de uma tal forma que, um dia, alguém disse assim: 'dá um tempo, que tu não tá na BM', sabe."

Podemos compreender que o processo de mortificação do eu busca não obliterar a eficiência do aparelho policial, buscando desenvolver a devoção ao bem-estar da instituição também pelo distanciamento dos objetos visados pela operação burocrática. Assim as praças ficam reduzi- 
das a mero número, desprovidas de qualidade (Bauman, 1998b): os seres humanos perdem sua identidade, pois os objetos humanos da execução de tarefas burocráticas são vistos com indiferença ética, e objetos desumanizados não podem ter uma causa, muito menos uma causa justa, ou apresentar alguma reivindicação de subjetividade.

\section{Efetivação da Aprendizagem das Jornadas de Instruções Militares}

É na rua, no policiamento ostensivo, que as policiais confrontam-se com as ações legais e ilegais, onde o trabalhar desenvolve-se no "estado de liminaridade". Servir à noite ou ao dia ganha diferentes visibilidades, desde o controle sustentado pela hierarquia, ao controle da comunidade. É na rua, preferencialmente à noite, onde ocorre o momento em que o currículo do militarismo, o currículo "oculto", o qual desenvolveu a supressão dos direitos individuais e a mentalidade do inimigo, associados à volatilização do estranho (Bauman, 1998a), efetiva o ser mulher policial militar:

"Inexoravelmente despertou como um guerreiro selvático que viu a morte pessoal e experimentou a nulidade da instituição democrática. É agora submisso à lei da selva e, portanto, pode retornar a polis. Na selva, pareceria que o uso excessivo da força se faz natural, instituindo a competição extrema como núcleo das relações de poder. Nesse ritmo batismal podemos supor que cumpriu-se uma passagem, subjetivamente emergiu na obediência esperada" (Albuquerque; Machado, 2001:14).

A matriz institucional/cultural está presente no exercício discricionário do/a policial; o ato de complementaridade necessária entre a norma legal e ação individual, decorrente de uma "livre escolha" ou do julgamento do indivíduo em função de um determinado objeto, problema ou moral, traz a inscrição da cultura:

“Acho que a ocasião faz o ladrão. Então, eu, na noite, já apanhei, já bati. Também é uma coisa que tu te desconhece, mas, no dia, é diferente. Acontece também, sabe, mas as formas, digamos assim, até as técnicas aplicadas, as técnicas policiais, são diferentes, porque é uma outra situação, até, porque durante o dia, tu não pode (...) policial agir com violência, quem disser que não, tá mentindo, pra própria segurança da gente, se tu já não chegar na noite empurrando, gritando, dizendo o que eles querem ouvir, porque não é com educação que a gente consegue nada. Eles não entendem este linguajar que a gente usa assim no dia-a-dia. A lingua- gem dele é outra né, então, tem que chegar assim, se não, a gente se dá mal.”

Pelos relatos, observamos que todo o processo de incorporação e integração das mulheres-praças ao aparelho policial está marcado por uma compreensão binária de igual e unitário, construída em uma noção de desigualdade que esconde o múltiplo jogo de diferenças, mantendo sua irrelevância e invisibilidade. Essa prerrogativa aparece sustentada nas "novas" concepções de segurança pública, com afirmativas segundo as quais a feminilidade, além de predispor as mulheres para determinado tipo de trabalho, determina que elas não são violentas nas práticas do policiamento ostensivo.

Observamos que esse processo de naturalização sobrepõe-se, inclusive, aos relatos de ações violentas concretizadas pelas próprias mulheres e estende-se para além dos muros do quartel. A esse respeito, em pesquisa realizada por Cônsul, investigando o posicionamento da comunidade quanto à inserção feminina na polícia militar, constatou-se que um dos primeiros quesitos apontados foi a "docilidade feminina" e que as mulheres são mais educadas, gentis, como se as diferenças que caracterizam o gênero fossem definidas por atributos conferidos por atribuições biológicas essenciais. Como aponta Fonseca (2000a:116), supõe-se que tudo que existe dentro de cada categoria - masculino/feminino - componha uma unidade que suprime/reprime, por conseguinte, as possíveis diferenças existentes em cada uma das categorias.

O processo de inserção feminina no aparelho policial militar passa por um processo de formatação, o qual podemos chamar de policização, modelo hegemônico com o qual não há uma ruptura. Assim, nesse sentido, não podemos falar de "processo de singularização" no interior do aparelho policial, da forma como Guattari e Rolnik (1986) utilizam o conceito. O processo de constituição de mulheres em policiais militares revela o aparelho policial como uma máquina de produção da subjetividade, impedindo qualquer forma de singularização, tanto para policiais masculinos como policiais femininos. Para as singularizações, existem sanções, portanto, o aparelho policial militar é um espaço que busca modos hegemônicos de ser e tem a violência como um dispositivo estratégico na constituição de homens e mulheres em policiais militares.

\section{CONSIDERAÇÕES FINAIS}

Sabemos que, no Brasil, é muito incipiente o debate acerca das modalidades de mecanismos de integração social, largamente adotados, nos Estados Unidos da América, sob 
a denominação de affirmative action (ação afirmativa) e, na Europa, referidos como discrimination positive (discriminação positiva) e action positive (ação positiva). Deveríamos avançar nesse debate como forma de alavancarmos a inserção feminina nas polícias militares brasileiras, porém enquanto discussão articulada às questões das reformas policiais, sobretudo compreendendo o aparelho policial militar enquanto uma nova tecnologia da produção social na constituição de mulheres em policiais.

Como um instrumento da modernidade, o aparelho policial militar é representativo e emblemático da coerção estatal, trazendo consigo a burocracia e a racionalidade instrumental características do modo de produção capitalístico e funcionando como um modelizador da subjetivação. Nesse sentido, a cultura do aparelho, enquanto dispositivo estratégico de um discurso dominante, ocupase da sujeição subjetiva das próprias pessoas que o compõem, no intuito de prepará-las para o desempenho do ofício de polícia. Contudo, a sobredeterminação militar nesse ofício não funciona como uma passagem para a vida militar, uma vez que o ofício policial não está definido para ações militares. Por meio dessa concepção, pode-se dar visibilidade ao grande conflito das polícias militares brasileiras, as quais incorporam novas exigências democráticas, mas, ao mesmo tempo, resistem em perder seus vínculos profundos com o militarismo.

Portanto, aqui, o rito de militarização não constitui um marco divisório de pertença ao espírito policial, afinal, essa militarização não é um exercício próprio da polícia (Tavares dos Santos, 1997), mas encontra, na violência, o dispositivo estratégico constituinte de homens e mulheres em policiais militares.

A evidência de um processo de constituição de mulheres em policiais militares leva-nos a reconhecer que as transformações que o mundo do trabalho vem sofrendo não podem ser reduzidas somente às perdas econômicas, pois elas se refletem igualmente na construção dos sujeitos. Nesse contexto, observamos que o gênero deve ser compreendido como elemento constitutivo das relações sociais, abrigado por um conceito eminentemente relacional que dá visibilidade à construção social dos modos de tornar-se homem e de tornar-se mulher. Assim, nos constituímos homens e mulheres nas mais diversas instituições ao longo de nossas vidas. Dessa forma, a inserção feminina nas polícias militares brasileiras, sustentada na visão de que há um modo natural de ser mulher e de que as mulheres, enquanto minoria simbólica, terão papel saneador na instituição e o não-reconhecimento do papel da instituição policial militar na constituição de mulheres em policiais, levam-nos a perceber a crise nas "novas" concepções de segurança pública e práticas sociais e a refletir sobre quais pilares construiremos a noção de segurança cidadã.

\section{NOTAS}

A autora é Coordenadora Regional/RS do Centro de Estudos de Segurança e Cidadania da Universidade Candido Mendes/RJ, para a pesquisa em desenvolvimento sobre Mulheres Policiais: impactos da participação feminina nos quadros das polícias militares brasileiras. Pesquisa financiada pela Fundação Ford, sob coordenação nacional de Barbara Soares.

1. Por meio de levantamento realizado em bancos bibliográficos, localizamos as seguintes referências sobre mulheres policiais militares: Maia (1993); e Meneli (1991). Além desses, cinco trabalhos sobre o tema foram encontrados nas próprias polícias militares, entre as monografias de formação de oficiais, quatro no Instituto de Pesquisa da Brigada Militar de Porto Alegre e um no Instituto de Pesquisa da Polícia Militar do Mato Grosso. Estes não aparecem nos bancos de dados de produção acadêmica, nem nos sistemas de busca pela Internet. Destacamos: Cônsul (1999); Rechden (2001); Bengochea (1992); Borneo (1991); e Machado (2001).

2. Cf. Calazans (2003). Dissertação concluída no âmbito do projeto Alternativas democráticas para o ofício de policia no século XXI (Tavares dos Santos, 2003).

3. JIM ou Campo: espaços de treinamento baseados em técnicas de sobrevivência.

\section{REFERÊNCIAS BIBLIOGRÁFICAS}

ALBUQUERQUE, C.F.L.; MACHADO, E.P. O currículo da selva: ensino, militarismo e ethos guerreiro nas academias brasileiras de polícia. Revista de las disciplinas del Control Sócial I. Capítulo Criminológico, v.29, n.4, p.5-33, 2001.

ANTUNES, R. Adeus ao trabalho? Ensaio sobre as metamorfoses e a centralidade do mundo do trabalho. 8. ed. São Paulo: Cortez; Campinas: Editora da Universidade Estadual de Campinas, 2002.

Os sentidos do trabalho: ensaio sobre a afirmação e a negação do trabalho. 6. ed. São Paulo: Boitempo, 1999.

BAUMAN, Z. O mal-estar da Pós-Modernidade. Rio de Janeiro: Zahar, $1998 \mathrm{a}$. 1998 b.

BENGOCHEA, J.L. et al. O desempenho da policial militar feminina $e$ a recepção da sociedade frente a esta nova realidade. Monografia. IPBM/RS, 1992. (Curso de Aperfeiçoamento de Oficiais).

BISOL, J.P. Foraclusão institucional. In: MARIANO, B.D. (Org.). Policia desafio da democracia brasileira. Porto Alegre: 2002.

BORNEO, J.L. et al. Vinculação administrativa e/ou operacional das policiais militares femininas da região sul. IPBM/RS, 1991.

BROWN, J. Criminatory experiences of woman police. A comparison of officers serving in England and Scotland, Wales, Morthern Ireland and the Republic of Ireland. International Journal of Sociology of Law, Academy Press, v.28, n.2, Jun. 2000. 
. Delinquency and deviant social behaviour. British Journal of Criminology, v.38, n.2, Spring, 1998.

European Police Woman: a comparative research perspective. UK: Departament of Psycology, University of Surrey, 1997.

. Integrating women into policing: a comparative European perspective. Disponível em:

$<$ http://www.ncjrs.org/policing/int627.htm>. Acesso em: ago. 2002

CALAZANS, M.E. de. A constituição de mulheres em policiais: um estudo sobre policiais femininas na Brigada Militar do Rio Grande do Sul. Dissertação (Mestrado) - UFRGS, Programa de PósGraduação em Psicologia Social e Institucional, Porto Alegre, 2003.

CONCURSO PMFem /Mato Grosso, 2001. Disponível em: $<$ http://www.clube7.com.br/body.php? cod=exibenews\&ID=72>.

CÔNSUL, J.C. Estilo de comando das oficiais da Brigada Militar da região metropolitana de Porto Alegre. Dissertação (Mestrado em Administração) - PPGA/UFRGS, Porto Alegre, 1999.

COSUELO, G.J. La mujer en la guardia civil, una perspectiva sociológica. Revista Española de Investigaciones Sociológicas, n.59, p.223-241, jul./set. 1992.

DELHOMEZ, G. La police au féminin. Publications du Centre d'Etudes et Recherches Sur la Police, Université de Reims, Faculté des Lettres et Sciences Humaines, 1991. Thèse pour le Doctorat 3. cycle. Education et Culture.

FERNÁNDEZ, M.M. Mujeres policía. Madrid, Centro de Investigaciones Sociologicas, Siglo XXI de España, n.134, 1994.

FONSECA, T.M.G. Modos de trabalhar modos de subjetivar. Tempos de reestruturação produtiva: um estudo de caso. In:____ (Org.). Modos de trabalhar modos de subjetivar. tempos de reestruturação produtiva. Porto Alegre: UFRGS, 2002. p.13-27. 2000a.

Gênero, subjetividade e trabalho. Petrópolis: Vozes,

Utilizando Bourdieu para uma análise das formas (in)sustentáveis de ser homem e mulher. In: STREY, M. et al. Construções e perspectivas em gênero. São Leopoldo: Unisinos, 2000b. p.19-32.

. Subjetivação na perspectiva da diferença: heterogênese e devir. Educação e Realidade. Revista da Educação da UFRGS, Porto Alegre, p.62-71, jan./jun. 1999.

GUATTARI, F.; ROLNICK, S. Micropolitica: cartografias do desejo. Petrópolis: Vozes, 1986.

HALL, S. A centralidade da cultura: notas sobre as revoluções culturais de nosso tempo. Educação \& Realidade, Porto Alegre, v.22, n.2, p.15-46, 1997.

KAUFMANN, P. (Ed.). Dicionário enciclopédico de psicanálise: o legado de Freud e Lacan. Rio de Janeiro: Zahar, 1996. p.213-5.

MACHADO, F. Polícia militar feminina em Mato Grosso. Várzea Grande - MT, Academia de Polícia Militar Costa Verde, 2001.

MAIA, L.R. Polícia feminina - perfil e ambigüidade da mulher militar na organização: assistência ou repressão? Dissertação (Mestrado) - Faculdade de Administração/PUC, São Paulo, 1993.

MELMAN, C. Alcoolismo, delinqüência, toxicomania: uma outra forma de gozar. 2. ed. São Paulo: Escuta, abr. 2000.

MENELI, P.R. A construção do gênero feminino e a alteração de seu papel social. Dissertação - (Mestrado em Criminologia) - PUCRS, Porto Alegre, 1991.

MEYER, D.E. Escola, currículo e produção de diferenças e desigualdades de gênero. Cadernos Temáticos - gênero, memória e docência. Prefeitura Municipal de Porto Alegre, Secretaria Municipal de Educação, 2001. p.29-35.

NUMMER, F.V. A condição feminina no espaço masculino. In: A experiência do curso de formação na construção de um saber ser soldado da Brigada Militar. Dissertação (Mestrado) - Programa de Pós-Graduação em Antropologia Social do IFCH/UFRGS, Porto Alegre, 2001.

PRENZLER, T. Woman and policing: policing emplication from us experience. Founded with the assistence of the Queensland, 2000. (Research and Police Paper, n. 3).

RECHDEN, S. et al. Militares estaduais femininas: rotinas de emprego das praças, nos órgãos de Polícia Militar de Polícia Ostensiva da Brigada Militar do Estado do Rio Grande do Sul. Jun. 2001. (Curso Avançado de Administração Policial Militar).

ROLNIK, S. Toxicômanos de identidade: subjetividade em tempo de globalização. In: LINS, D.S. (Org.). Cultura e subjetividade: saberes nômades. Campinas: Papirus, 1997. p.19-24.

Uma insólita viagem à subjetividade: fronteiras com a ética e a cultura. In: LINS, D.S. (Org.). Cultura e subjetividade: saberes nômades. Campinas: Papirus, 1997. p.25-34.

Machos \& fêmeas. In: LINS, D.S. (Org.). A dominação masculina revisitada. Campinas: Papirus, 1998. p.69-72.

Tristes gêneros. In: LINS, D.S. (Org.). A dominação masculina revisitada. Campinas: Papirus, 1998. p.63-68.

SOARES, B. Mulheres policiais: impactos da participação feminina nos quadros das polícias militares brasileiras. Pesquisa em desenvolvimento. Centro de Estudos de Segurança e Cidadania, Universidade Candido Mendes e Fundação Ford. Coordenadora Regional, Rio Grande do Sul, Márcia Esteves de Calazans.

TAVARES DOS SANTOS, J.V. (Coord.). Alternativas democráticas para o ofício de polícia no século XXI. Porto Alegre, IFCH/ UFRGS, set. 2003. (Relatório final de pesquisa financiada pela Fundação Ford. Versão I).

Microfísica da violência, uma questão social mundial. Ciência e Cultura. Revista da SBPC - Sociedade Brasileira para o Progresso da Ciência, São Paulo, ano 54, n.1, p.22-24, jul. 2002. (Núcleo temático: Violência).

. Novas questões sociais mundiais, projetos sociais e culturais e a planificação emancipatória. Revista Humanas, Porto Alegre, IFCH/UFRGS, v.24, n.1-2, p. 163-185, jan./dez. 2001.

A arma e a flor: formação da organização policial, consenso e violência. Tempo Social - Revista de Sociologia da USP, São Paulo, FFLCH/USP, v.9, n.1, p.155-167, maio 1997.

A violência como dispositivo de excesso de poder. Revista Sociedade e Estado, Brasília, UnB, v.10, n.2, p.281-298, jul./ dez. 1995.

Cidadania dilacerada. Revista Crítica de Ciências Sociais, Coimbra, n.37, p.131-46, jun. 1993.

WALTER, B.F. Uniform-Order: Schwierigkeit, eine Mannerdomane zu sturmen, Die Polizei. Dez. 1999. p.357.

WORTMANN, M.L.C. O uso do termo representação na educação em Ciências e nos Estudos Culturais. Proposições, Campinas, v.12, n.1, p.151-161, 2001.

ZAMAKONA, E.B. El personal policial feminino en la ertzaintza 1999. Revista Técnica del Ertzaintza, HARLAX, Onati-Espanha, n.2, p.47-97, 2000.

Márcia Esteves de Calazans: Psicóloga-Pesquisadora, Integrante do Grupo de Pesquisa Violência e Cidadania da IFCH/UFRGS. 